\title{
ESTADO DE SITIO E ELEIÇõES
}

\author{
Cartão do emerito jurisconsulto DR. Clovis \\ Bevilaqua.
}

Aos illustres collegas, Drs. João Arruda e Braz de Sousa Arruda, Clovis Bevilaqua, saúda cordialmente e agradece a remessa do substancioso e magnifico estudo sobre "Estado de sitio e eleições", que conservará entre os trabalhos escolhidos, para opportuno aproveitamento.

Rio, 28 de Agosto de 1918.

Carta do grande constitucionalista chileno, Dr. D. Alcibiades Roldan, professor de Dreito Constitucional na Universidade de Santiago.

Alcibiades Roldan saluda attentamente al doctor don Braz de Sousa Arruda y le agradece el envio del ejemplar del diario "O Estado de S. Paulo", correspondiente al 15 de julio último, al mismo tiempo que las lisonjeras referencias al libro "Derecho Constitucional de Chile" hechas en el interessante estudio acerca del "Estado de sitio e eleições", publicado en dicho diario y con cuyas conclusiones se encuentra perfectamente conforme.

Santiago, 2 de Agosto de 1918.

\section{CONSULTA}

Podem ser feitas eleições nols Estados, durante o estado de sitio decretaido pela União Federal?

\section{PARECER}

Não nos occuparemos com a extensão que deve ser dada á medida excepcional adoptada pela União, e a que se refere a consulta. $O$ continuo forcejo do grande mestre no assumpto, o conselheiro Ruy Barbosa, tem sido improficuo para levar a bom caminho os governos que se têm succedido desde o tempo do marechal Floriano (Docs. Parl., Estado de Sitio, v. 6, pags. 359 e segs.) 
até hoje. Não discutiremos se é, ou não, licito estabelecer a censura postal e a dos jornaes. Diremos só como tem sido interpretado o artigo da Constituição que faculta, este tremendo remedio que, melhor fôra, julgamos, acompanhando grandes e sensatos constitucionalistas, haver sido della riscado. (Estado de Sitio, v. 6, pags. 375 e segs.). Geralmente têm entendido os interpretes e executores de nossa Constituição ser o estado de sitio a mesma "suspensão dos direitos garantidos pela lei fundamental", com maior ou menor extensão, segundo o espirito mais ou menos despotico de quem o decreta (Barbalho, pags. 120 e segs.). E' caso em que não devemos applicar a regra do Direito Romano "Minime sunt mutanda quœ interpretationem certam semper habueruut" (De legibus, fr. 23). Corre-nos, ao contrario, o dever de dar á Constituição o sentido liberal que lhe tem sido attribuido pelo conselheiro Ruy Barbosa, inspirando-se na Americana, fonte da nossa (loc. cit., pag. 379).

Ao tempo do marechal Floriano, particularmente na luctuosa revolta da armada, entendeu-se que o estado de sitio suspendia o direito de manifestar o pensamento pela tribuha, além de terem sido declarados sem garantia "direitos essénciaes", como sejam o de dignidade (esbofeteando-se jornalistas, castigando-se com a palmatoria homens respeitaveis que formulavam reclamações contra o desleixo da Estrada de Ferro Central, obrigando-se deputados a carregar sobre a cabeça vasos de materias fecaes, ou, como se dizia então, "a levar cubos fazendo a fachina da prisão"), e o de vida (arcabuzando-se, sem processo, os suspeitos, factos que se repetiram particularmente no Rio de Janeiro, em Santa Catharina e, em Paraná, na Lapa, onde se deu o morticinio comparado pelos escriptores da época ao de Quinteros, mancha da Argentina). O estado de sitio do marechal Hermes foi particularmente destinado a ser applicado aos jornalistas que ridicularizavam esse chefe, dando-lhe o typo de um 
Nero moderno, menos feroz, mas muito mais tolo do que o successor de Claudio. E' tambem a figura que deixou para a Historia a palavra inspirada do conselheiro Ruy Barbosa, comparavel, em belleza, senão superior á de Suetonio, o historiador dos Doze Cesares (Est. de Sitio, v. 7). No ultimo estado de sitio, o actual, augmentaram-se as restricçóes, pois a censura postal, feita ao tempo do marechal Floriano em fórma de abuso da Repartição do Correio, se tornou official, á imitação da que se fez. na Europa conflagrada. Manteve-se a censura á imprensa. Declarouse tambem, do mesmo modo que nos anteriores, suspenso o direito de liberdade, no sentido de direito de locomoção ou "jus manendi, ambulandi, et eundi ultro citroque". Não tem havido, é certo, violencias, graças ao espirito pacifico do actual presidente, e seria injustiça comparar o governo de hoje com o do marechal Hermes, em que se realizou "o negro e sanguinoso crime do "Satellite", horrenda mancha na civilização deste paiz". (Est. de Sitio, v. 7, pag. 427). Se não tem havido violencias tragicas, actos sanguinosos, em compensação a censura á imprensa tem sido levada a extremo. Não procura ella acautelar a segurança externa do Brasil, nem este se acha em perigo, como demonstrou o conselheiro Ruy Barbosa, mas amordaça toda critica aos actos governamentaes. Basta abrir qualquer jornal, para perceber que a censura tem sido destinada a criar uma nuvem que occulte aos olhos do povo bra'sileiro tudo quanto se passa nas regióes do poder. O povo vive ás escuras, e o partido da opposição ficou inteiramente privado de fazer a nação conhecer as idéas que elle tem sobre a direcção das coisas publicas. Deu-se isto que Novicow (Justiça) comparou á ablação de um lobulo cerebral do paiz, comparação repetida por mais de uma vez pelo nosso grande jurisconsulto, o exmo. sr. dr. Pedro Lessa, hoje juiz no Supremo Tribunal Federal. Sem a imprensa ficará sujeita a nossa estremecida Patria a seguir a rota que mais conveniente parecer aos 
seus actuaes governantes. Não podemos deixar de transckever, a este proposito, as palavras do conhecidissimo Bryce: "Personne ne peut dire qu'on a refusé de l'entendre, ni se bercer de l'espoir que le monde l'approuvera, quand il l'aura entendu. Sous un gouvernement tyrannique, le sentiment du tort subit, et de l'injustice nourrit la flamme de la resistance chez une minorité persecutée. Mais, dans un pays comme celui-là, où la liberté de la presse, le droit de réunion publique et le droit d'association et d'agitation ont été étendus par les lois et servent, tous les jours, plus que dans aucun autre pays du monde, il n'y a rien qui reveille ce sentiment." (Bryce, La République Américaine. trad. f. de Lestang., v. 3, pag. 468).

Ao lado, porém, deste silencio imposto pelo actual governo, allegando precisar preparar a defesa do paiz contra o possivel ataque de estrangeiros, ha, no povo, o receio de qualquer abuso da autoridade, que não poderá ser cohibido pelos meios judiciaes, suspensos como se acham muitos delles, entre os quaes o remedio do "habeas-corpus", tendo nossos tribunaes, e entre elles o de S. Paulo, decidido, aliás muito bem, que, com o estado de sitio, não poderiam tomar contas á policia das prisões por esta effectuadas de individuos suspeitos. (Rev. dos Tribunaes, v. 25, pag. 46).

Sendo assim, vamos demonstrar que a eleição com voto livre não póde ser feita nessas condições, pois os eleitores estarão em justo, e de nenhum modo vão témor de qualquer violencia por parte do poder publico, que geralmente considera os adversarios politicos como sendo seus inimigos merecedores de ser atacados pela força organizada para defender a patria, como bem diz o grande constitucionalista Cooley: "Enemy must generally be the party out of the power" (Constitucional Limitations, pag. 925). 
A liberdade de voto foi sempre a preoccupação dos grandes publicistas. Passemos em revista os povos cultos. Refere Hello, que escreveu no principio do seculo XIX, ser o systema da compra do voto acceito na Inglaterra, e, logo em seguida, explica entender por compra de voto o estar o eleitor sujeito á influencia de um chefe, homem de idéas politicas, e que procurará; no Parlamento, fazer victoriosas suas opiniões sobre o mais conveniente para a nação. Diz Hello que este systema, que elle denomina da "venalidade eleitoral", e que nos parece uma persistencia dos grupos primitivos, sendo o chefe apenas o correspondente ao "paterfamilias" romano, ou ao patrono de época posterior em relação aos clientes (Bonfante, Hermann Post e Bonjean), e de nenhum modo o corruptor de eleitores, se depura pela elevação de idéas dos eleitos. Para nós, porém, isto está longe de ser embaraço á liberdade de voto. Póde o eleitor inglês, do mesmo modo que o cliente romano ou qualquer outro membro de grupo politico (Bryce, La Rép. Amér., v. 3, pags. 200 e segs.) abandonar, quando lhe aprouver, o chefe, e votará com outra agremiação, restando ao abandonado dizer, como disse o romano consultado pelos que na vespera haviam dado seus votos a outro candidato: "Omnes consulere scitis, consulem facere nescitis". Não podemos comprehender como sem liberdade de voto se possa ter um governo livre e que represente devidamente o pensamento do paiz. A Inglaterra de hoje muito se modificou, segundo vemos nas obras de estrangeiros que se impressionaram profundamente com os actuaes costumes inglêses, e entre os notaveis escriptores poderemos apontar Ramalho Ortigão (John Bull) que, com tanta felicidade, dando-nos idéa da origem ou da razão de ser do regimen representativo, naquelle paiz, não lhe poude comtudo, leigo como era no assumpto, comprehender o verdadeiro valor; e o conselheiro Ruy Barbosa, já em suas "Cartas da Inglaterra", em que nos mostra a in- 
fluencia lá exercida pela religião christan, já em outros muitos trabalhos em que nos descreve a evolução por que tem passado o regimen em uma constante democratiżação, em um crescente liberalismo. Hoje comprehende-se a conhecidissima anecdota de Stuart Mill sobre o valor de seu voto comparado ao de seu cocheiro, e portanto podemos concluir não só que os inglêses têm clara idéa da necessidade de manter sempre o voto livre, mas tambem que obtiveram, sob varias fórmas, pudessem os eleitores sempre manifestar sua vontade nas urnas sem a menor pressão, agrupados, ou não, em torno de um chefe que houvessem livremente escolhido.

Se é á America do Norte que deveremos sempre pedir lições em materia constitucional e em outras de ordem politica, cumpre-nos ouvir os constitucionalistas e os tribunaes americanos acerca da materia que nos occupa. Devemos lembrar-nos ao estudar o Direito Americano, de que o unico direito que se suspende naquella Republica, por nós imitada só nos defeitos, e não nas muitas qualidades, é o direito de impetrar "habeas-corpus" (Barbalho, Const. pag. 121; Black's, Constitucional Law, n. ${ }^{\circ}$ 274). Note-se mais que "it seems to be settled that the power to suspend the writ... is confided to congress alone... and that it does not belong to the executive branch of the governement... unless under an authorization from congress, (Black, loc. cit.). Em sua obra "Direito Constitucional", diz Cooley: "Uma eleição falta a seus legitimos fins quando os eleitores se acham sujeitos a influencias taes que se obrigam á abstenção do voto, ou então a darem-no inconscientemente em virtude de razões illicitas ou corruptoras, ou sob a influencia do medo ou da coacção. (Trad. de Alcides Cruz, pag. 301). Nessa mesma obra, occupa-se com o segredo do voto, um dos meios de assegurar ao eleitor sua liberdade. $\mathrm{Na}$ "Constitutional Limitations", ao tratar da liberdade eleitoral (The freedom of elections) observa ser esta uma 
das capitaes preoccupaçôes das leis da livre Republica: "To keep every election free of all the influences and sourroundings which might bear improperly upon it, or might impel electors to cast their suffrages otherwice than their jugements would dictate, has always been a prominent object in american legislation". Accrescenta que, tendo já falado da necessidade de segredo no voto, tem a dizer das providencias mais ou menos severas adoptadas pelos diversos Estados da União para' segurança da liberdade de voto: "It is provided by the constitutions of several of the states bribery of an elector shall constitue a disqualification of the right to vote or to hold office; the threating of an elector, with a view to influence his vote..." Prosegue e termina dizendo que se procurou sempre a mais completa liberdade no exercicio do voto "with a view to secure the most completely free and unbiassed expression of opinion that shall be possible". (C. XVII). Não faltam decisões dos tribunaes, condemnando as fraudes fundadas em pressão sobre os eleitores, julgando comprehendidas as pressões sobre eleitores na fórmula: "To conspire, to injure, oppress, threaten, or intimidate any citizen in the free exercise of any right, a privilege secure to him by the constitution" (U. S. Rep. n. ${ }^{\circ}$ 238, pag. 383). Nos Estados Unidos é tal o rigor em assumptos eleitoraes, que "on inflige d'autres peines, mais plus légères, à ceux qui "payent un repas aux électeurs". (Bryce, v. 3; pag. 200).

$\mathrm{Na}$ Columbia, o professor Burgess ensina que a maior cautela dos verdadeiros amigos do regimen republicano é a verdade eleitoral, com a mais completa liberdade de voto "To secure an honest, independent intelli. gent vote" (Political Science, v. 2, pag. 111).

Não é menos claro o grande constitucionalista chileno Alcibiades Roldan, ao accupar-se das regalias dos que tomam parte numa elëição, lembrando que "son inviolables los miembros de las juntas, comisiones ó 
colegios electorales." (Derecho Constitucional de Chile, n. ${ }^{\circ}$ 59). Difficil será comprehender-se que haja individuos inviolaveis em estado de sitio, quando, ao menos entre nós, até os representantes da nação se acham sujeitos a fazer a limpeza das prisões, como se fossem presos da peior especie.

$\mathrm{Na}$ Argentina, sustenta Gonzalez Calderon, não se poder conceber governo republicano sem a representação da vontade popular por uma eleição sem vicios. Eis o que ensina o mestre na vizinha Republica: "Y para que en efecto sean los representantes de esa voluntad, el sufragio no debe encontrar-se contaminado por vicios que lo anulen o lo desnaturalicen. La violencia, el fraude, la simulacion lo corrompen o lo suprimen, y, en consecuencia, el gobierno republicano falla por su base. En esta forma politica surge el sufragio de su naturaleza misma, pues se deriva necesariamente de la soberania del pueblo, de manera que las leyes electorales deben tener por principal objectivo asegurar su pureza y la libertad del ato en que se manifieste, siendo necesario, además, cualificar prudentemente al elector, desde que desempeña la funcion primordial y de mayor transcendencia para los destinos del pais." (Derecho Constitucional, v. 1, pag. 2, C. 4.). E' pois o exercicio do voto, e este na' fórma mais livre possivel, que constitue, se nos é permittida a expressão, a alma do regimen republicano, no entender do grande publicista da Republica Argentina.

Ainda mesmo nas monarchias, é a verdade eleitoral a preoccupação de todos os espiritos liberaes e dos governos moralisados. Não mencionaremos senão a Italia, tendo-nos já referido fugidiamente á Inglaterra, Lá, como diz Orlando, os regulamentos são destinados a evitar as fraudes, e a cabala eleitoral (il broglio) mas, quando se consumma uma illegalidade, soffrem os infractores da lei penas "le quali, per nostro ordinamento, sono assai gravi". Menciona, entre os muitos factos pas- 
siveis de pena, "corruzione, pressione, abuso di autoritá, violenze e vie di fatto, turbamento della votazione, frodi in genere".

Em nosso Codigo Penal, encontramos os arts. 165 e segs. destinados a manter a liberdade completa do voto.

Isto posto, perguntamos se é possivel que se admitta liberdade da parte do eleitor em um paiz onde qualquer autoridade poderá, sem que contra o acto tenha o cidadạ̃o recurso de nenhuma especie, prendel-o e mantel-o incommunicavel, se tal eleitor fôr adversario, o que equivale, segundo o autor acima citado, a ser inimigo, ou estar fóra da lei, e dentro das prescripções do decreto de estado de sitio? Dir-se-á que será um "vão temor" do cidadão, e que portanto contra elle se acha a regra juridica do Direito Romano de que não se annulla o acto praticado sob vão temor (R. J., fr. 184). Passamos a responder. "Tem-se cantado, não sei em quantas cordas da musica, da adulação e da baixeza, a benignidade do estado de sitio. E' um regimen, dizem, de agua de rosas, uma invenção mirifica e regeneradora... A arnaia miuda, a desprezivel plebe dos cidadãos brasileiros, ahi se acha, pelas ruas sujeita ao arbitrio de qualquer autoridade, que, no desafogo de uma vindicta, das menos confessaveis, póde recolher um brasileiro á cadeia, como se recolhe um criminoso, um réu de policia ao xadrez policial, sem que se saiba porque, sem que haja outra justificativa a não ser a de que estamos em estado de sitio" (Ruy Barbosa, Docs. Parl., Est. de Sitio, v. 7, pag. 394).

Admittamos que o corpo eleitoral tinha a certeza de que nenhuma autoridade inferior teria a audacia de uma violencia; admittamos que estaria na convicção de que o chefe da União seria incapaz de mudar de idéas, differindo nisto de tantos outros que começaram o governo na maior brandura e o terminaram ensanguentando o solo do paiz; admittamos que o maior respeito seria dado.aos eleitores, e que um esquecimento completo, haveria da 
parte do governo em relação aos eleitores que houvessem votado no candidato da opposição. Dado tudo isto, ainda não poderiamos affirmar ter sido a eleição feita com liberdade de voto. Facil é de se entender que a eleição só póde ser consideraḍa como feita com escolha livre do candidato, se as qualidades de cada um puderem ser apreciadas sem peias pela imprensa e pelos oradores na tribuna publica. Ora, basta abrir os jornaes para ver que a nossa censura nada fica a dever ás mais severas da Europa conflagrada, e que tal censura se mostra de um rigor draconiano, não contra qualquer manifestação de pensamento que poderia comprometter a segurança da patria ameaçada por estrangeiros, mas contra qualquer critica, por mais leve que seja, ao pessoal que se acha no governo. Os successos de Pennapolis estão ahi eloquentemente a provar que não houve liberdade de tribuna no ultimo pleito eleitoral travado em S. Paulo, liberdade sem a qual, é impossivel eleição livre, manifestação da vontade popular com conhecimento pleno do acto.

A tudo isto deveremos juntar uma consideração que nos parece de peso. A Constituição Federal, em seu art. 28, garante a representação da minoria, e o Supremo Tribunal tem muitas vezes decidido que tudo quanto é concedido pela Const. Fed. aos juizes federaes, se entende outorgado aos estaduaes, donde concluimos que o mesmo argumento é applicavel aos representantes dos Estados nos respectivos congressos estaduaes. Assim sendo, é obvio que não se póde admittir um pleito eleitoral em que o partido da opposição se ache em condições inferiores ao do governo, e a inferioridade da opposição é manifestada quando sobre o paiz pesa um decreto de sitio, ainda que se trate de estado de sitio mirifico, como diz o conselheiro Ruy Barbosa, uma vez que os eleitores da opposição pódem receiar qualquer violencia (sereno quoque caelo, aliquando tonat), e não têm meios de se informar 
sobre as qualidades dos candidatos contrarios ao partido governamental. (Bryce, v. 3, pag. 468).

Lembremo-nos de que o proprio marechal Floriano, suspendia o estado de sitio, quando se devia effectuar uma eleição.

Dir-se-á que deste modo não poderemos ter jámais eleições, salvo requisitando, a espaços, do governo federal, o estadual, uma suspensão do estado de sitio, para os actos eleitoraes. Responderemos que isto é o resultado de haver sido fraudada a Constituição Federal, desde o tempo do marechal Hermes, o primeiro que teve um estado de sitio perenne, contra o disposto no art. 80 da Constituição Federal, que deveria ter sido interpretado "civiliter", quando diz que será o estado de sitio "por tempo determinado". Lembremo-nos de que na antiga Roma, em tempo de pouca cultura; o poder do dictador não excedia a seis mezes.

E' este o parecer sincero que podemos dar, com a coragem da profissão e a certeza de que cumprimos nosso dever de cidadãos, promptos a tudo sacrificar pela $\mathrm{Pa}$ tria' e pela Lei Fundamental que todos devemos respeitar, sob pena de vermos dissolvida a sociedade brasileira.

Sujeitamol-o á correcção dos doutos.

S. Paulo, 15 - Julho - 1918.

JoÃo Arruda.

Braz de Sousa Arruda. 